\title{
Характеристики эмоционального выгорания и увлеченность форумными ролевыми играми у менеджеров
}

\author{
Л.С. Глинкина \\ Российский государственный педагогический университет им. А.И. Герцена \\ gsI uba@yandex.ru
}

\section{Аннотация}

Статья посвящена проблеме взаимосвязи характеристик эмоционального выгорания с увлеченностью форумными ролевыми играми у менеджеров. Сотрудники, переживающие эмоциональное выгорание, нередко прибегают к таким неконструктивным стратегиям его преодоления, как зависимое поведение (к которым относится и увлеченность компьютерными играми) и другим формам отклоняющегося поведения.

59 случайных русскоговорящих менеджеров по всему миру приняли участие в исследовании, включавшем в себя MBI, CIAS и ряд других тестов, включая демографическую анкету и вопросы, посвящённые активности на форумных ролевых играх. В результате они были разделены на две группы: увлеченных и не увлеченных. В статье приводятся результаты анализа характеристик эмоционального выгорания у менеджеров увлеченных и не увлеченных форумными ролевыми играми: так у увлеченных больше выражены аддиктивные склонности и уровень эмоционального выгорания, но его симптоматика предстает более узкой. Также показаны взаимосвязи между различной симптоматикой эмоционального выгорания с аспектами игровой деятельности и различными видами аддикций в среде менеджеров.

Ключевые слова: эмоциональное выгорание, компьютерная зависимость, менеджер, компьютерная игра, форумная ролевая игра

Библиографическая ссылка: Глинкина Л.С. Характеристики эмоционального выгорания и увлеченность форумными ролевыми играми у менеджеров // Информационное общество: образование, наука, культура и технологии будущего. Выпуск 3 (Труды XXII Международной объединенной научной конференции «Интернет и современное общество», IMS-2019, Санкт-Петербург, 19-22 июня 2019 г. Сборник научных трудов). - СПб: Университет ИТМО, 2019. С. 226- 235. DOI: $10.17586 / 2587-8557-2019-3-226-235$

\section{1. Увлеченность компьютерными играми как коррелят эмоционального выгорания}

По данным релиза Международного союза электросвязи (МСЭ), опубликованного в декабре 2018 г., количество пользователей Интернета в мире составляет 3,9 млрд. человек или 51,2\% населения планеты [1]. Из этого можно заключить, что мир начала XXI века для жителей стран развитого мира практически полностью превратился в мир цифровой эпохи, а киберпространство (под этим термином понимают совокупность всех информационных ресурсов, доступных посредством сети Интернет) перестало быть исключительно электронной средой для хранения, обработки и передачи информации. На нынешний момент оно так же является источником порождения новых гибридных форм творческой деятельности. Киберпространство стало своеобразной формой «промежуточного пространства», расширяющего внутренний психический мир человека [2]. У людей, 
чрезмерно вовлеченных в киберпространство, размываются личностные границы, и они воспринимают компьютер уже как часть своей личности, тем самым формируя аддиктивное поведение. Таким образом, Интернет и компьютер, как новые явления привнесли в наш мир и новые виды зависимостей: интернет-зависимость и зависимость от компьютерных игр, частным видом которых являются форумные ролевые игры (FRPG).

Традиционной классификацией компьютерных игр является классификация по жанрам. Одним из жанров, входящих в данную классификацию, являются ролевые игры (RPG) игры в которых человек берет на себя роль какого-либо персонажа и развивает его в мире с заданными характеристиками [3]. Рядом психологов именно эти игры признаются провоцирующими аддикции из-за второго компонента - «принятия роли» - и механизмов самоиндефикации игрока с персонажем [4].

Также существует несколько классификаций компьютерных игр по психологической составляющей, одной из которых является классификация, предложенная О.А. Поповым в 2009 г. Он выделил четыре типа компьютерных игр, находящихся на пересечении двух основных осей: «наличия-отсутствия персонажа» и «наличия-отсутствия морального выбора». Форумные ролевые игры, согласно ей, следует отнести к первому типу игр: игры с наличием и персонажа, и морального выбора. Считается, что именно такой тип игр вызывает наибольшее привыкание [5].

Форумная ролевая игра - это разновидность текстовой ролевой игры (не имеющей материального компонента в виде декораций, костюмов и т.д.), проводящаяся на вебфорумах, т.е. в сети Интернет. В процессе этой игры ее участники создают условнолитературное [6] сетевое произведение во взаимодействии друг с другом на общем «сеттинге», имеющим заранее обговоренные характеристики среды-декорации, в которой происходит игра: место, время и условия взаимодействия.

Участие в такого рода играх, как и в любых других компьютерных играх, оказывает неоднозначное влияние на их участников. Одни исследователи рассматривают компьютерные игры как средство, помогающее в социальной адаптации, и способ обучения [7-11], другие же говорят о пристрастии к компьютерным играм, как о виде копингстратегии, организованной по типу избегания, в том числе, и рабочих обязанностей $[12,13]$. Чрезмерная рабочая нагрузка и различные производственные стрессы, взаимодействуя с личностными и социальными факторами, в определенных ситуациях, приводят к ментальному и физическому истощениям, что по К. Кондо и является эмоциональным выгоранием [14].

Считается, что термин «эмоциональное выгорание» (в англ. оригинале burnout) впервые был введен американским психиатром Г. Фрейденбергером в 1974 г. Это открытие стало значительным прорывом в психологии, так как эмоциональное выгорание приносит обществу убытки, как экономические, так и психоэмоциональные [15]. С тех пор многие психологи внесли свой вклад в изучение данного феномена. Эмоциональное выгорание, изначально считавшееся свойственным лишь кругу хелперских профессий [16], было обнаружено у специалистов всех профессиональных областей [17] и даже за пределами профессиональной деятельности [18].

В ряде исследований показано, что сотрудники, переживающие эмоциональное выгорание, нередко прибегают к таким неконструктивным стратегиям его преодоления, как зависимое поведение (к которым относится и увлеченность компьютерными играми) и другим формам отклоняющегося поведения [19-23]. Но систематических исследований посвящённых данной проблеме в отечественной психологии практически не наблюдается [24]. Фактически нет работ, посвященных психологическим проблемам увлеченности форумными ролевыми играми. 


\section{2. Предварительное исследование пространства форумных ролевых игр}

В проведенном нами пилотажном исследовании приняли участие 58 игроков форумных ролевых игр. Для определения личностных характеристик, играющих мы использовали следующие методики:

— «индекс жизненного стиля» Плутчика-Келлермана-Конте,

- методика Леонгарда - Шмишека,

- анкета психографического характера, так же включавшая в себя вопросы об активности на форумных ролевых играх.

Анализ данных показал, что большинство игроков форумных ролевых игр являются женщинами (около 77\%) в возрасте от 17 до 29 лет. Выявившая половозрастная неравномерность выборки согласуется с исследованием И. Гамбургера и Е. Бен-Артзи [25]. Среди играющих наиболее часто встречаются такие типы акцентуаций характера, как: застревающий, дистимный, циклотимный и аффективный (см. таблицу 1).

Таблица 1. Средние баллы выраженности акцентуаций у игроков форумных ролевых игр

\begin{tabular}{|l|l|}
\hline \multicolumn{1}{|c|}{ Тип акцентуации } & Средний балл \\
\hline демонстративный тип & 12,9 \\
\hline застревающий тип & 14,5 \\
\hline педантичный тип & 10,8 \\
\hline возбудимый тип & 12,7 \\
\hline гипертимный тип & 12,5 \\
\hline дистимический тип & 13,5 \\
\hline тревожно-боязливый тип & 11,2 \\
\hline циклотимный тип & 17,9 \\
\hline аффективный тип & 16,8 \\
\hline эмотивный тип & 13,6 \\
\hline
\end{tabular}

Застревание и дистимность являются чертами характера, способствующими развитию эмоционального выгорания, это было подтверждено в ряде работ, к примеру, в работах В. Л. Малыгина [26] и Т. В. Рединой [27]. У игроков повышен уровень общей напряженности психологических защит $(45,6 \%)$, что можно расценить как сильное переживание играющими стрессовых ситуаций.

Несмотря на общее разнообразие профессий играющих, большинство из них предстают по типологии Климова как тип «человек-человек». К этому типу профессий относятся и менеджеры, которых мы выбрали для дальнейшего исследования.

\section{2. Характеристики эмоционального выгорания и увлеченность форумными ролевыми играми у менеджеров: результаты эмпирического исследования}

\section{1. Характеристики исследования}

На основе данных пилотажного исследования и данных, полученных в результате предварительного включенного скрытого наблюдения за игроками в среде FRPG и их внеролевым общением во внеигровых разделах форумов, были выдвинуты следующие гипотезы: 
- существует взаимосвязь между степенью эмоционального выгорания и вовлеченностью менеджеров в форумные ролевые игры;

- существуют особенности проявления эмоционального выгорания у менеджеров, увлеченных форумными ролевыми играми.

Предметом эмпирического исследования являлась взаимосвязь эмоционального выгорания и увлеченности форумными ролевыми играми, а объектом выступили менеджеры молодого возраста, увлеченные и не увлеченные форумными ролевыми играми. Целью нашего исследования стало изучение взаимосвязи профессионального выгорания с особенностями игровой активности менеджеров, увлеченных форумными ролевыми играми.

В эмпирическом исследовании приняли участие 59 отличных от предыдущей выборки добровольцев, 35 из которых являлись действующими игроками форумных ролевых игр, оставшиеся же 24 составили контрольную группу. Все респонденты являлись различного вида менеджерами. Средний стаж ролевой активности у игроков - 10,2 года. Остальные характеристики выборки представлены в таблице 2.

Таблица 2. Социально-демографические характеристики респондентов

\begin{tabular}{|c|c|c|c|c|c|}
\hline \multirow{2}{*}{ Распределение респондентов } & \multirow{2}{*}{$\begin{array}{l}\text { Все } \\
\text { Количество }\end{array}$} & \multicolumn{2}{|l|}{ Игроки } & \multicolumn{2}{|l|}{ Неиграющие } \\
\hline & & Количество & $\%$ & Количество & $\%$ \\
\hline \multicolumn{6}{|l|}{ По полу } \\
\hline Мужчины & 11 & 3 & 8,6 & 8 & 33,3 \\
\hline Женщины & 48 & 32 & 91,4 & 16 & 66,7 \\
\hline Итого & 59 & 35 & & 24 & \\
\hline \multicolumn{6}{|l|}{ По возрасту } \\
\hline $19-25$ & 35 & 20 & 57,1 & 15 & 62,5 \\
\hline $26-32$ & 22 & 14 & 40,0 & 8 & 33,3 \\
\hline Старше 32 & 2 & 1 & 2,9 & 1 & 4,2 \\
\hline \multicolumn{6}{|l|}{ По образованию } \\
\hline Школьное полное & 4 & 3 & 8,6 & 1 & 4,2 \\
\hline Среднее специальное & 6 & 5 & 14,3 & 1 & 4,2 \\
\hline Высшее & 49 & 27 & 77,1 & 22 & 91,6 \\
\hline \multicolumn{6}{|c|}{ По стажу работы на последнем месте } \\
\hline Меньше 3 лет & 44 & 27 & 77,1 & 17 & 70,8 \\
\hline Больше 3 лет & 15 & 8 & 22,9 & 7 & 29,2 \\
\hline
\end{tabular}

Для определения уровня выгорания и его качественных характеристик были использованы методики MBI (общая версия) и методика В. В. Бойко. Для диагностики аддиктивных склонностей использовались шкала CIAS (адаптация В.Л. Малыгина, К.А. Феклисова.) и методика Г.Б. Лозовой, помимо этого, респондентам была предложена методика личностного дифференциала с инструкцией: «опишите себя по предложенным критериям». Целью использования последней методики служило определение личностных характеристик респондентов. Респонденты-игроки также заполняли дополнительную анкету о специфических особенностях их игры, в которую входило копирование анкет их персонажей, эти анкеты подверглись контент-анализу с целью обнаружения проявления 
симптомов эмоционального выгорания в текстах. Для статистической обработки данных использовались U-критерий Манна-Уитни и коэффициент корреляции Спирмена.

\section{1. Результаты сравнительного анализа менеджеров, увлеченных и не увлеченных форумными ролевыми играми}

В результате сравнительного анализа менеджеров, увлеченных и не увлеченных форумными ролевыми играми, выявлено, что у менеджеров, увлеченных форумными ролевыми играми, больше выражен общий уровень эмоционального выгорания (U=286,0, $\mathrm{p}=0,04$ по интегральной оценке MBI) и такие его проявления как эмоциональнонравственная дезориентация $(\mathrm{U}=290,0, \mathrm{p}=0,05)$, расширение сферы экономии эмоций $(\mathrm{U}=274,0, \mathrm{p}=0,02), \quad$ эмоциональная отстраненность $(\mathrm{U}=226,0, \quad \mathrm{p}=0,00), \quad$ редукция профессиональных достижений $(\mathrm{U}=269,5, \mathrm{p}=0,02$ и $\mathrm{U}=233,0 \mathrm{p}=0,00$ по Бойко и по MBI, соответственно) и эмоциональное истощение $(\mathrm{U}=291,5, \mathrm{p}=0,05)$.

Также было выявлено, что играющие менеджеры менее склонны к зависимости от межполовых отношений $(\mathrm{U}=275,5, \mathrm{p}=0,03)$, но более склонны к другим видам зависимого поведения $(U=232,0, p=0,00)$, в частности, это лекарственная $(U=177,0, p=0,00)$, пищевая $(\mathrm{U}=284,0, \mathrm{p}=0,04)$ и компьютерная аддикции $(\mathrm{U}=34,5, \mathrm{p}=0,00$ по методике Г.Б. Лозовой и $\mathrm{U}=170,0, \mathrm{p}=0,00$ по шкале CIAS). Увлеченные форумными ролевыми играми менеджеры ниже оценивают свою личностную активность $(\mathrm{U}=187,5, \mathrm{p}=0,00)$.

Далее мы проанализировали группы увлеченных форумными играми менеджеров и не увлеченных по отдельности (см. таблицы 3, 4). В обеих группах были обнаружены гендерные различия.

В группе не увлеченных мужчины больше, чем женщины подвержены лекарственной зависимости, а женщины больше подвержены зависимости от компьютера.

В группе увлеченных форумными ролевыми играми у женщин меньше наблюдаются симптомы аддиктивного поведения химического спектра: лекарственной зависимости, наркотической зависимости и табакокурения. Характерным явлением для форумных ролевых игр также является перевес женского кросспола - когда женщины играют мужских персонажей, мужчины же больше проявляют симптоматику профессионального выгорания в своих постах: деперсонализацию и редукцию профессиональных достижений.

Таблица 3. Значимые гендерные различия у увлеченных FRPG менеджеров

\begin{tabular}{|l|l|l|}
\hline \multicolumn{1}{|c|}{ Характеристика различия } & \multicolumn{1}{|c|}{$\mathbf{U}$} & p-value \\
\hline Как часто вы отыгрываете кросспол? & 9,0 & 0,02 \\
\hline Лекарственная зависимость & 12,0 & 0,04 \\
\hline Зависимость от курения & 14,0 & 0,05 \\
\hline Наркотическая зависимость & 8,5 & 0,02 \\
\hline Деперсонализация контент & 11,0 & 0,03 \\
\hline $\begin{array}{l}\text { Редукция профессиональных достижений } \\
\text { контент }\end{array}$ & 5,5 & 0,01 \\
\hline
\end{tabular}

Таблица 4. Значимые гендерные различия у не увлеченных FRPG менеджеров

\begin{tabular}{|c|c|c|}
\hline Характеристика различия & $\mathbf{U}$ & p-value \\
\hline Лекарственная зависимость & 30,0 & 0,04 \\
\hline $\begin{array}{lcl}\text { Зависимость } & \text { от } \\
\text { социальных сетей) } & \text { компьютера } & \text { (интернета, } \\
\end{array}$ & 20,5 & 0,0 \\
\hline
\end{tabular}

У «долгоработающих» менеджеров, увлеченных форумными ролевыми играми, сильнее выражена зависимость от здорового образа жизни $(U=55,0, p=0,04)$, у них увеличен объем 
ролевых сообщений $(\mathrm{U}=43,0, \mathrm{p}=0,01)$, сильнее выражена симптоматика деперсонализации в постах $(U=43,0, p=0,01)$, и стаж их ролевой деятельности оказался длиннее $(U=50,0, p=0,02)$.

Не увлеченные форумными ролевыми играми менеджеры с длительным стажем работы на одном месте обнаруживают меньшие склонности к религиозной $(U=28,0, p=0,05)$ и наркотической зависимости $(\mathrm{U}=24,5, \mathrm{p}=0,03)$, помимо этого у них меньше выражен такой симптом выгорания как психосоматические и психовегетативные нарушения $(\mathrm{U}=20,5$, $\mathrm{p}=0,01)$.

У увлеченных форумными ролевыми играми менеджеров с высоким уровнем выгорания наблюдается ощущение скуки $(U=83,0, p=0,02)$ и трудности в жизни $(U=88,0, p=0,04)$. При этом эмоциональное выгорание проявляется не по всему спектру симптоматики, а лишь по его части, а именно: в неудовлетворенности собой $(U=59,5, p=0,00)$, в загнанности в клетку $(\mathrm{U}=69,5, \mathrm{p}=0,007)$, в неадекватном избирательном эмоциональном реагировании $(\mathrm{U}=48,5$, $\mathrm{p}=0,00)$, в эмоциональном дефиците $(\mathrm{U}=69, \mathrm{p}=0,01)$, в эмоциональной отстраненности $(\mathrm{U}=79,0, \mathrm{p}=0,02)$ и в личностной отстраненности $(\mathrm{U}=33, \mathrm{p}=0,00)$.

У не увлеченных же респондентов картина предстает несколько другой: у выгоревших наблюдаются симптомы развития толерантности к компьютеру $(\mathrm{U}=24,0, \mathrm{p}=0,05)$, и они оценивают себя как менее сильных $(U=24, p=0,05)$ и меньше уважают себя $(U=17,5, p=0,02)$. У них симптомами являются: переживание психотравмирующих обстоятельств $(\mathrm{U}=4,5$, $\mathrm{p}=0,00)$, неудовлетворенность собой $(\mathrm{U}=13, \mathrm{p}=0,01)$, загнанность в клетку $(\mathrm{U}=18,5, \mathrm{p}=0,02)$, тревога и депрессия $(U=23,5, p=0,05)$, расширение сферы экономии эмоции $(U=2, p=0,00)$, редукция профессиональных обязанностей $(\mathrm{U}=11,5, \mathrm{p}=0,01)$, эмоциональный дефицит $(\mathrm{U}=2,5, \mathrm{p}=0,00)$ и эмоциональная отстраненность $(\mathrm{U}=20,5, \mathrm{p}=0,03)$, психосоматические и психовегетативные нарушения $(\mathrm{U}=20,0, \mathrm{p}=0,03)$, а также личностная отстраненность $(\mathrm{U}=6,0$, $\mathrm{p}=0,00)$.

\section{1. Результаты корреляционного анализа в группе увлеченных форумными ролевыми играми}

С целью обнаружить связи между особенностями игры и различными аспектами реальности были проанализированы ответы играющих респондентов.

Обнаружены связи различных симптомов выгорания с характеристиками ролевой активности. Этими связями являются: связь силы ощущения тревоги и депрессивных настроений с потерей контроля над временем во время пребывания на ролевых играх $(\mathrm{R}=0,464, \mathrm{p}=0,01)$, связь переживания обстоятельств, как психотравмирующих, с предпочтением игр один-на один с партнером $(\mathrm{R}=0,350, \mathrm{p}=0,05)$, связь личностной отстраненности с ощущением затруднений поиска решений трудностей, возникающих в реальности $(\mathrm{R}=0,522, \mathrm{p}=0,01)$, связь неудовлетворённости с собой с установкой, что с людьми легче общаться онлайн $(\mathrm{R}=0,356, \mathrm{p}=0,05)$; связь неадекватного эмоционального реагирования с установкой, что с людьми легче общаться онлайн $(\mathrm{R}=0,370, \mathrm{p}=0,05)$, c замещением беспокоящих мыслей о реальности игрой $(\mathrm{R}=0,482, \mathrm{p}=0,01)$ и с ощущением трудностей в реальности $(\mathrm{R}=0,446, \mathrm{p}=0,01)$; связь расширения сферы экономии эмоций с текущим количеством персонажей $(\mathrm{R}=0,422, \mathrm{p}=0,05)$, связь эмоционального дефицита с текущим количеством персонажей $(\mathrm{R}=0,613, \mathrm{p}=0,01)$, связь психосоматических и психовегетативных нарушений с наличием желания привлечь своих друзей в ролевой мир $(\mathrm{R}=0,404, \mathrm{p}=0,05)$ и с текущим количеством персонажей $(\mathrm{R}=0,464, \mathrm{p}=0,01)$. Ощущение загнанности в клетку коррелирует с наличием трудностей в реальности $(\mathrm{R}=0,464, \mathrm{p}=0,01)$, эмоциональное истощение - c потерей контроля над временем $(\mathrm{R}=0,380, \mathrm{p}=0,01)$, a личностная отстраненность - с наличием трудностей в реальности $(\mathrm{R}=0,522, \mathrm{p}=0,01)$. Общий уровень выгорания также связан с ощущением трудностей в реальности $(\mathrm{R}=0,500$, $\mathrm{p}=0,01)$.

Также были обнаружены: связь силы характера с наличием друзей-ролевиков в реальности $(\mathrm{R}=0,345, \mathrm{p}=0,05)$, обратная связь среднего количества персонажей с 
трудоголизмом $(\mathrm{R}=-0,376, \mathrm{p}=0,05)$, обратная связь уровня самооценки с количеством текущих персонажей $(\mathrm{R}=-0,391, \mathrm{p}=0,05)$.

Количество упоминаний симптомов эмоционального выгорания в постах так же коррелируют с некоторыми аспектами реальности. Количество упоминаний симптомов эмоционального истощения в постах коррелирует с потерей контроля над временем во время пребывания на играх $(\mathrm{R}=0,436, \mathrm{p}=0,01)$ и выраженностью игровой зависимости $(\mathrm{R}=0,601, \mathrm{p}=0,01)$. Количество упоминаний симптомов деперсонализации в постах коррелирует со стажем игры $(\mathrm{R}=0,384, \mathrm{p}=0,05)$, симптомами игровой зависимости $(\mathrm{R}=0,371$, $\mathrm{p}=0,05)$ наличием других хобби $(\mathrm{R}=0,513, \mathrm{p}=0,01)$, наличием друзей-ролевиков в реальности $(\mathrm{R}=0,345, \mathrm{p}=0,05)$ и потерей контроля над временем $(\mathrm{R}=0,353, \mathrm{p}=0,05)$. Количество упоминаний симптомов редукции профессиональных достижений коррелирует с потерей контроля над временем во время пребывания на играх $(\mathrm{R}=0,570, \mathrm{p}=0,01)$ и симптомами лекарственной $(\mathrm{R}=0,448, \mathrm{p}=0,01)$ и алкогольной зависимостей $(\mathrm{R}=0,511, \mathrm{p}=0,01)$.

Отдельно стоит отметить связь среднего объема постов с общей склонностью к аддикциям $(\mathrm{R}=0,511, \mathrm{p}=0,01)$ и такой чертой как компульсивность $(\mathrm{R}=0,372, \mathrm{p}=0,01)$ и обратную связь кросспола с зависимостью от межполовых отношений $(\mathrm{R}=0,396, \mathrm{p}=0,05)$. Так же интересен факт, что игроки, скрывающие свое увлечение FRPG, менее нравственно дезориентированы $(\mathrm{R}=-0,418 \mathrm{p}=0,05)$.

\section{3. Заключение}

Полученные результаты исследования показывают: менеджеры, увлеченные форумными ролевыми играми, выгорают иначе, нежели их коллеги, не увлеченные FRPG. Особенности их увлеченности связаны с различными аспектами эмоционального выгорания, а само эмоциональное выгорание помимо химических зависимостей может сопровождаться так же и поведенческими видами аддикции, в частности, компьютерноигровой.

Менеджеры, увлеченные форумными ролевыми играми, выгорают иначе, нежели их коллеги, не увлеченные форумными ролевыми играми. Симптоматика у увлеченных форумными ролевыми играми менее обширна, а «основной удар» приходится на эмоциональную и социальную сферы в виде: неудовлетворенности собой, ощущения загнанности в клетку, неадекватного избирательного эмоционального реагирования, эмоционального дефицита и эмоциональной отстраненности, а также личностной отстраненности.

У менеджеров же, не увлеченных форумными ролевыми играми, выгорание «бьет» по большему количеству аспектов жизни. Они более склонны рассматривать ситуации на работе, как психотравмирующие, у них сильнее выражены симптомы тревоги и депрессии, они больше не удовлетворены собой, что приводит, в том числе, к проблемам с самоценкой и оценкой своих сил. Так же у них редуцируется профессиональные навыки равно, как и сфера эмоций: они ощущают себя загнанными в клетку, расширяют сферу экономии эмоций и испытывают эмоциональный дефицит. Вдобавок у них формируется толерантность к пребыванию за компьютером.

В своей работе мы не рассматривали другие виды игр, отличные от FRPG и другие профессиональные группы, отличные от менеджеров, а поэтому нельзя с точностью сказать: являются ли полученные нами результаты специфическими или их можно экстраполировать и на другие виды компьютерных игр и другие профессиональные группы. Сравнение полученных нами данных с аналогичными данными для других комплементарных групп является перспективой дальнейшего изучения.

Несмотря на полученные нами данные о связи эмоционального выгорания с игровой динамикой, остаются неясными мотивы прихода людей в среду играющих. По нашей оценке, ориентировочный возраст присоединения будущих участников FRPG к сообществу ролевиков - 16-17 лет, что по Э. Эриксону соответствует кризису индентичности. Связь 
разрешения этого кризиса с увлеченностью FRPG также можно рассматривать как перспективу дальнейших изысканий.

\section{Литература}

[1] TADVISER Государство. Бизнес. IT URL: http://www.tadviser.ru/ index.php/Статья:Интернет-доступ_(мировой_рынок) (дата обращения 16.03.2019)

[2] Алексенко Н. Н. Психоаналитические аспекты поведения человека в киберпространстве // Сумма психоанализа. 2000. С. 152-167.

[3] Аветисова А. А. Психологические особенности игроков в компьютерные игры // Психология. Журнал высшей школы экономики. 2011. Т. 8. №. 4. С.35-58.

[4] Иванов М.С. Влияние ролевых компьютерных игр на формирование психологической зависимости от компьютера / М.С. Иванов // Психология зависимости. - Минск, 2004. C. $152-175$.

[5] Попов О. А. Новая классификация компьютерных игр URL: https://psystat.at.ua/publ/4-10-30 - 2009. (дата обращения 03.03.2019).

[6] Олесина Е. П. Сетература-новая форма или новый смысл? // Мир психологии. 2014. №.4. C. 183-193.

[7] Фомичева Ю. В., Шмелев А. Г., Бурмистров И. В. Психологические корреляты увлеченности компьютерными играми // Вестник МГУ. Сер. 1991. Т. 14. С. 27-39

[8] Решетникова О. Зависимость от компьютера // Школьный психолог. 2006. №. 19. C. 45-48.

[9] Шапкин С. А. Компьютерная игра: новая область психологических исследований // Психологический журнал. 1999. Т. 20. №. 1. С. 86-102.

[10]Тендрякова М. В. Старые и новые лики игры: игровая специфика виртуального пространства // Культурно-историческая психология. 2008. №. 2. С. 60-68.

[11]Тихомиров О.К., Лысенко Е.Е. Психология компьютерной игры // Новые методы и средства обучения. 1988 №. 1. М.: Знание. С. 30-66.

[12]Kardefelt-Winther D. The moderating role of psychosocial well-being on the relationship between escapism and excessive online gaming // Computers in Human Behavior. 2014. Vol. 38. - C. 68-74.

[13]Зарецкая О. В. Зависимость от компьютерных онлайн-игр как разновидность аддиктивного поведения // Social Psychology \& Society. - 2016. - Т. 7. - №. 3. C. 105-120.

[14]Kondo K. Burnout syndrome // Asian Medical Journal. 1991. - T. 34. - №. 11. P. 627-633.

[15]Качан Г. А. Синдром профессионального выгорания как фактор развития стресса. Фундаментальные и прикладные проблемы стресса: материалы междун. науч.-практ. конф., Витебск, 10 июня 2010 г. - Витебск. 2010. С. 129-131.

[16]Schabracq M. et al. (ed.). The handbook of work and health psychology. - J. Wiley \& Sons, 2003. P. 438-463.

[17]Maslach C., Schaufeli W. B., Leiter M. P. Job burnout // Annual review of psychology. -2001. Vol. 52. №. 1. P. 397-422.

[18]Längle A. Burnout-Existential meaning and possibilities of prevention // European Psychotherapy. 2003. Vol. 4. №. 1. P. 107-121.

[19]Belcastro P. A. Burnout and its relationship to teachers' somatic complaints and illnesses // Psychological Reports. 1982. Vol. 50. №. 3_suppl. P. 1045-1046.

[20]Parker P. A., Kulik J. A. Burnout, self-and supervisor-rated job performance, and absenteeism among nurses // Journal of Behavioral Medicine. 1995. Vol. 18. №. 6. P. 581-599.

[21]Ahola K. et al. Alcohol dependence in relation to burnout among the Finnish working population // Addiction. 2006. Vol. 101. №. 10. P. 1438-1443.

[22]Kuerer H. M. et al. Career satisfaction, practice patterns and burnout among surgical oncologists: report on the quality of life of members of the Society of Surgical Oncology // Annals of surgical oncology. 2007. Vol. 14.№. 11. P. 3043-3053. 
[23]Kristanto T., Chen W. S., Thoo Y. Y. Academic burnout and eating disorder among students in Monash University Malaysia // Eating behaviors. 2016. Vol. 22. P. 96-100.

[24]Шлычков В. Р., Шлычкова О. Н. Формирование профессиональных деформаций и развитие аддиктивных форм поведения личности (взаимосвязь, диагностика, коррекция) // Акмеология. 2015. №. 4 (56) С.199-208.

[25]Hamburger Y. A., Ben-Artzi E. The relationship between extraversion and neuroticism and the different uses of the Internet // Computers in human behavior. 2000. Vol. 16. №. 4. P. 441449.

[26]Малыгин В. Л. и др. Влияние личностных особенностей и копинг-стратегии при синдроме эмоционального выгорания у врачей психиатров и наркологов // Прикладные информационные аспекты медицины. 2008. Т. 11. №. 1. С. 76-83.

[27]Редина Т. В. Эмоциональное выгорание педагогов специальных коррекционных образовательных учреждений // Знание. Понимание. Умение. 2010. №. 1. С. 222-227.

\title{
Characteristics of Burnout and Forum-role-playing-games Enthrallment Among Managers
}

\author{
L.S. Glinkina
}

\section{Herzen State Pedagogical University of Russia}

The article is devoted to the problem of the relation between the characteristics of managers' burnout and their forum-role-playing-games enthrallment. Employees experiencing burnout often use unconstructive ways of coping such as addictive behavior (which includes computer games enthrallment) as well as other forms of deviant behavior.

A random sample of 59 Russian-speaking managers around the world completed surveys that included the Maslach Burnout Inventory, Chen Internet Addiction Scale and some other tests as well as demographic questions and questions designed to conduct characteristics of their roleplaying activity. They were classified into one of two groups: forum-role-playing and not-forumrole-playing. Results of our study indicated numerous differences of the characteristics of burnout and addiction between these groups. Forum-role-playing managers have more prominent burnout level, but a variety of experiencing by them symptoms is narrower. We've also investigated the relationship of various symptoms of burnout to aspects of gaming activity and different types of addictions among managers.

Keywords: burnout, computer addiction, computer games, manager, forum role-playing game

Reference for citation: Glinkina L.S. Characteristics of Burnout and Forum-role-playing-games Enthrallment Among Managers // Information Society: Education, Science, Culture and Technologies of the Future. Vol. 3 (Proceedings of the XXII International Joint Scientific Conference «Internet and Modern Society», IMS-2019, St. Petersburg, June 19-22, 2019). St. Petersburg: ITMO University, 2019. P. 226 - 235. DOI: 10.17586/2587-8557-2019-3-226-235

\section{Reference}

[1] TADVISER Gosudarstvo. Biznes. IT URL: http://www.tadviser.ru/index.php/ Статья:Интернет-доступ_(мировой_рынок) (access date: 16.03.2019) (In Russian).

[2] Aleksenko N. N. Psihoanaliticheskie aspekty povedeniya cheloveka v kiberprostranstve // SUMMA PSIHOANALIZA. - 2000. - S. 152-167. (In Russian).

[3] Avetisova A. A. Psihologicheskie osobennosti igrokov v komp'yuternye igry // Psihologiya. Zhurnal vysshej shkoly ekonomiki. - 2011. - T. 8. - №. 4. S.35-58 (In Russian).

[4] Ivanov M.S. Vliyanie rolevyh komp'yuternyh igr na formirovanie psihologicheskoj zavisimosti ot komp'yutera / M.S. Ivanov // Psihologiya zavisimosti. - Minsk, 2004. - S. 152-175. (In Russian). 
[5] Popov O. A. Novaya klassifikaciya komp'yuternyh igr URL: https://psystat.at.ua/publ/4-1-0-30 2009. (access date: 03.03.2019) (In Russian).

[6] Olesina E. P. Seteratura-novaya forma ili novyj smysl? // Mir psihologii. - 2014. - №. 4. - S. 183193 (In Russian).

[7] Fomicheva YU. V., SHmelev A. G., Burmistrov I. V. Psihologicheskie korrelyaty uvlechennosti komp'yuternymi igrami // Vestnik MGU. Ser. - 1991. - T. 14. - S. 27-39 (In Russian).

[8] Reshetnikova O. Zavisimost' ot komp'yutera // Shkol'nyj psiholog. - 2006. - №. 19. - S. 45-48 (In Russian).

[9] Shapkin S. A. Komp'yuternaya igra: novaya oblast' psihologicheskih issledovanij //Psihologicheskij zhurnal. - 1999. - T. 20. - №. 1. - S. 86-102 (In Russian).

[10] Tendryakova M. V. Starye i novye liki igry: igrovaya specifika virtual'nogo prostranstva //Kul'turno-istoricheskaya psihologiya. - 2008. - №. 2. - S. 60-68. (In Russian).

[11] Tihomirov O.K., Lysenko E.E. Psihologiya komp'yuternoj igry // Novye metody i sredstva obucheniya. 1988 №. 1. M.: Znanie. S. 30 -66. (In Russian).

[12] Kardefelt-Winther D. The moderating role of psychosocial well-being on the relationship between escapism and excessive online gaming // Computers in Human Behavior. - 2014. - T. 38. - P. 6874.

[13]Zareckaya O. V. Zavisimost' ot komp'yuternyh onlajn-igr kak raznovidnost' addiktivnogo povedeniya // Social Psychology \& Society. - 2016. - T. 7. - №. 3. S. 105-120 (In Russian).

[14] Kondo K. Burnout syndrome // Asian Medical Journal. - 1991. - T. 34. - №. 11. P. 627-633.

[15] Kachan G. A. Sindrom professional'nogo vygoraniya kak faktor razvitiya stressa. Fundamental'nye i prikladnye problemy stressa: materialy mezhdun. nauch.-prakt. konf., Vitebsk, 10 iyunya $2010 \mathrm{~g}$. - Vitebsk, 2010. - S. 129-131 - 2010. (In Russian).

[16] Schabracq M. et al. (ed.). The handbook of work and health psychology. - J. Wiley \& Sons, 2003. - P. 438-463.

[17] Maslach C., Schaufeli W. B., Leiter M. P. Job burnout // Annual review of psychology. - 2001. T. 52. - №. 1. - P. 397-422.

[18] Längle A. Burnout-Existential meaning and possibilities of prevention //European Psychotherapy. - 2003. - T. 4. - №. 1. - P. 107-121.

[19] Belcastro P. A. Burnout and its relationship to teachers' somatic complaints and illnesses // Psychological Reports. - 1982. - T. 50. - №. 3_suppl. - P. 1045-1046.

[20] Parker P. A., Kulik J. A. Burnout, self-and supervisor-rated job performance, and absenteeism among nurses // Journal of Behavioral Medicine. - 1995. - T. 18. - №. 6. - P. 581-599.

[21] Ahola K. et al. Alcohol dependence in relation to burnout among the Finnish working population // Addiction. - 2006. - T. 101. - №. 10. - P. 1438-1443.

[22] Kuerer H. M. et al. Career satisfaction, practice patterns and burnout among surgical oncologists: report on the quality of life of members of the Society of Surgical Oncology // Annals of surgical oncology. - 2007. - T. 14. - №. 11. - P. 3043-3053.

[23] Kristanto T., Chen W. S., Thoo Y. Y. Academic burnout and eating disorder among students in Monash University Malaysia // Eating behaviors. - 2016. - T. 22. - P. 96-100.

[24] Shlychkov V. R., Shlychkova O. N. Formirovanie professional'nyh deformacij i razvitie addiktivnyh form povedeniya lichnosti (vzaimosvyaz', diagnostika, korrekciya) // Akmeologiya. 2015. - №. 4 (56) S.199-208 (In Russian).

[25] Hamburger Y. A., Ben-Artzi E. The relationship between extraversion and neuroticism and the different uses of the Internet // Computers in human behavior. - 2000. - T. 16. - №. 4. - P. 441449.

[26] Malygin V. L. i dr. Vliyanie lichnostnyh osobennostej i koping-strategii pri sindrome emocional'nogo vygoraniya u vrachej psihiatrov i narkologov // Prikladnye informacionnye aspekty mediciny. - 2008. - T. 11. - №. 1. - S. 76-83. (In Russian).

[27] Redina T. V. Emocional'noe vygoranie pedagogov special'nyh korrekcionnyh obrazovatel'nyh uchrezhdenij // Znanie. Ponimanie. Umenie. - 2010. - №. 1. S. 222-227 (In Russian). 